\title{
Latinskaya Amerika: as relações entre a União Soviética e a América Latina $(1957-1962)^{1}$
}

\author{
Marcos Napolitano ${ }^{2}$
}

\begin{abstract}
Resumo: Este artigo analisa as relações políticas e culturais da União Soviética com a América Latina entre a segunda metade dos anos 1950 e o início dos anos 1960. Nesse período, a partir do "novo internacionalismo revolucionário", defendido por Nikita Krushev, a União Soviética ampliou sua presença no continente, conciliando diplomacia cultural, diplomacia comercial e apoio político aos nacionalistas por meio da ação dos Partidos Comunistas locais. Essa nova postura soviética procurou conciliar pragmatismo diplomático e visão ideológica da geopolítica mundial, nem sempre tendo sido articulada com sucesso. Outro aspecto abordado é o papel do nacionalismo e do "antiamericanismo" na América Latina, que coincidiu com a nova postura soviética, e exigiu mudanças na política externa dos Estados Unidos para o continente.
\end{abstract}

Palavras-chave: Relações, União Soviética, América Latina

\section{Latinskaya Amerika: Relations between the Soviet Union and Latin America (1957-1962)}

\begin{abstract}
This article analyzes the political and cultural relations of the Soviet Union with Latin America between the second half of the 1950s and the beginning of the 1960s. In this period, based on the theory of the "new revolutionary internationalism" advocated by Nikita Khrushchev, the Soviet Union linked cultural diplomacy, trade diplomacy and political support to the Latin-american nationalists groups, through the action of the local communist parties. This new Soviet diplomacy tried to reconcile pragmatism and ideological vision of world geopolitics. Another aspect of this context is the role of nationalism and "anti-Americanism" in Latin America, which coincided with the new Soviet diplomacy, and demanded changes in US foreign policy for the continent.
\end{abstract}

Keywords: Relations, Soviet Union, Latin America

Artigo recebido em: 06/03/2019

Artigo aprovado para publicação em: 06/09/2019

\footnotetext{
${ }^{1}$ Este artigo foi elaborado com apoio da bolsa "Produtividade em Pesquisa" (CNPq), Processo No 301618/2017-8.

${ }^{2}$ Professor Titular no Depto.de História da USP. Doutor em História Social.Bolsista de ProdutividadeCNPq. Email: napoli@usp.br
}

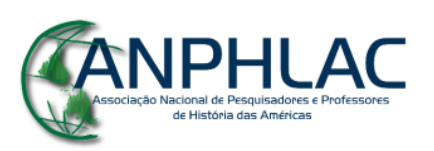


A história sobre os efeitos da Guerra Fria na América hispânica e no Brasil costuma ser pensada como um capítulo das relações históricas de dependência entre o Continente e os Estados Unidos. Embora tal abordagem não esteja equivocada, dada a inquestionável supremacia norte-americana e seu protagonismo econômico e militar no Continente, um outro player internacional central da Guerra Fria na América Latina costuma ser colocado em segundo plano: a União Soviética.

A visão de mundo da Guerra Fria foi construída por policy makers, think tanks e diplomatas em geral, tendo exercido forte influência na historiografia, tradicionalmente centrada no jogo diplomático e militar entre as duas superpotências e seus principais aliados (MUNHOZ, 2004). Mas é fato que novas abordagens destacaram a dimensão global que extrapolou o mundo restrito da diplomacia e da história das relações internacionais (WESTAD, 2000b; WESTAD, 2000a). Novas abordagens enfocam em visões de mundo, sistemas ideológicos e sistemas culturais como um todo (imprensa, universidade, artes), gerando amplo impacto no cotidiano das sociedades envolvidas. Além disso, permitem analisar a documentação diplomática para além das fri as razões de Estado, observando muitas formulações contidas nos documentos como expressão de valores e de representações culturais sobre si e sobre os outros. Ainda que nosso recorte documental neste artigo privilegie os documentos diplomáticos e de inteligência internacional, altamente regrados e protocolares, notamos que tais visões ideológicas e sistemas culturais atuam como componentes simbólicos essenciais dos conteúdos neles presentes.

Tornou-se lugar comum dizer que o triunfo da Revolução Cubana e seu alinhamento com a União Soviética alteraram as peças do xadrez da Guerra Fria na América Latina. Ainda assim, antes e depois desse evento capital na história do Continente, as relações deste com a superpotência comunista seriam marcadas pelo distanciamento, pautado pelo "fatalismo geográfico", que considerava a América Latina área de influência "natural" dos Estados Unidos, e o "pragmatismo diplomático", focado nas relações comerciais e diplomáticas de baixo perfil, “desideologizadas”. Muitos autores afirmam que a relação entre América Latina e URSS foi pragmática, determinada por fatores econômicos e políticos voltados à estabilidade da geopolítica mundial e da política interna soviética, restringindo os objetivos ideológicos e estratégicos de uma suposta expansão imperial global da superpotência comunista (MILLER, 1989). A ruptura cubana com o capitalismo e o governo de Salvador Allende no Chile costumam ser vistos

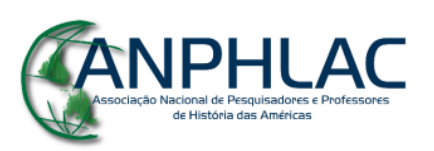


como casos pontuais e excepcionais da influência soviética na América Latina. Mesmo em relação a Cuba, Nicola Miller argumenta que a política soviética foi mais reativa do que proativa, e não deu o tom para a relação diplomática com os outros países do continente (MILLER, 1989: 4). Entretanto, vários casos nacionais, períodos e temas específicos continuam pouco estudados, como, por exemplo, o caso brasileiro e a atuação soviética na América Latina ao longo da chamada "Guerra Fria cultural” (RUPRECHT, 2011). Outros autores vão mais longe, afirmando que tal relação foi errática, limitada a certos momentos históricos e prejudicada pela ambiguidade da política externa soviética, ora voltada à relação Estado-Estado, ora voltada à instrumentalização dos Partidos Comunistas locais como braços de sua diplomacia global. Conforme Edmé Dominguez (DOMINGUEZ, 1995: 2):

Prior to 1959 Latin America was a region of low priority for the USSR. A sort of "geographic fatalism" led the USSR to believe that American hegemony made it impossible for any revolution to succeed in Latin America. Khrushchev, the one Soviet leader who would be responsible for Cuba's entrance into the Socialist community, did not even include Latin America in his February 1956 proposal for a Third World "zone of peace". However, since the 20s the Soviet Union had apparently followed a "two track policy:" state to state relations and support for revolution and solidarity with native Communist parties. Neither policy was particularly successful.

Essa visão, mesmo válida sob a perspectiva das relações Estado-Estado, tem sido criticada pela historiografia da Guerra Fria que surgiu a partir do final dos anos 1980 (BLASIER, 1987; PEDEMONT, 2015). O foco nos agentes não-estatais e nas relações culturais iluminou aspectos não destacados nessas relações. Assim, cabe-nos também perguntar qual seria o lugar efetivo desse espaço geopolítico e cultural que engloba as três Américas no conflito global entre as superpotências antes mesmo de 1959, e para além das relações "frias” interestatais. Mesmo no campo das relações internacionais oficiais, se é verdade que a América Latina não esteve no centro das preocupações da política externa do Kremlin entre 1945 e 1958, a partir desse ano novos influxos da política soviética em relação ao chamado "Terceiro Mundo" tiveram efeitos sobre essa parte do tabuleiro geopolítico mundial, considerada pela opinião pública um “quintal dos Estados Unidos”. Portanto, a janela de oportunidades aberta pela Revolução Cubana coincidiu com uma nova política soviética para o mundo, como veremos adiante. Ao longo dessa história cheia de variáveis conjunturais, anticomunismo e antisovietismo frequentemente se entrecruzaram por parte das elites políticas nacionais latino-americanas, alimentadas

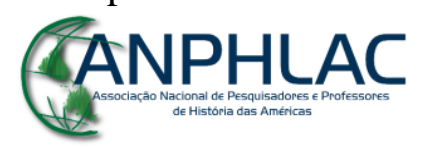


pela política de contenção global do comunismo por parte dos Estados Unidos (BAPTISTA JR, 2005). Mas não menos importante, e com especial força no período, foi o antiamericanismo (MCPHERSON, 2003), compartilhado não apenas por militantes comunistas pró-Moscou, mas por um conjunto de vozes nacionalistas que viam na aproximação com o bloco socialista a possibilidade de ampliar a independência econômica e diplomática.

A partir desses pressupostos historiográficos gerais, pretendo mapear um período chave na construção de uma nova geopolítica soviética para a América Latina - os anos de 1955 a 1962 - com implicações ideológicas, culturais e econômicas para o continente que se fizeram sentir até meados dos anos 1970. Esses anos são nomeados pela historiografia como o auge de um novo "internacionalismo revolucionário" soviético, sob o governo de Nikita Krushev, que convivia com a chamada "coexistência pacífica" entre socialismo soviético e capitalismo. Se tal fase da política externa soviética não chegou a provocar uma guinada radical no padrão prévio e posterior, marcado pelo pragmatismo e pela lógica de não interferir de maneira agressiva em zonas de influência do bloco oposto, ela é importante para compreender um momento particularmente tenso das relações entre os Estados Unidos e o continente latino-americano. Em outras palavras, questões como antiamericanismo, nacionalismo econômico, políticas reformistas ganharam um novo lugar nas políticas nacionais de vários países latino-americanos, atuando em meio às tensões geradas pelo novo internacionalismo soviético e pela reação norte-americana. A doutrina de contenção global do comunismo encontrava um terreno propício entre as elites civis e militares latino-americanas e brasileiras, já informadas por anticomunismo ferrenho antes da Guerra Fria (PATTO, 2002). As elites políticas e diplomáticas brasileiras se viam como um polo de moderação geopolítica na América do Sul, projetando o país como um parceiro estratégico (ainda que ressentido) dos Estados Unidos na defesa continental contra o comunismo (RODEGHERO, 2007).

Nos documentos soviéticos, a movimentação na direção da América Latina, a partir do final dos anos 1950, se concilia com a autoimagem de "país amigo dos povos oprimidos" pelo "imperialismo", ao mesmo tempo em que se diz respeitar a "autodeterminação dos povos" e a "coexistência pacífica" com o Ocidente, eixos da geopolítica soviética para ganhar espaço nas "zonas cinzentas", indefinidas ou hesitantes entre os dois blocos liderados pelas superpotências.

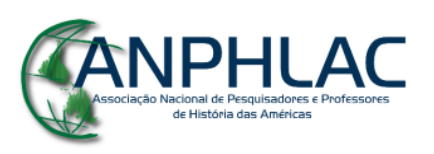


Tais projeções culturais e simbólicas acerca de si e dos outros, produzidas por diversos atores estatais e não-estatais, oriundos de muitas realidades nacionais e origens ideológicas, devem ser levadas em conta na constituição de uma história internacional sobre as relações entre União Soviética e América Latina. Essa perspectiva permite pensar tais relações para além da história diplomática tradicional, centrada nas elites diplomáticas e na ação dos Estados como entes jurídicos. Assim, emergiu no debate um conjunto de temas historiográficos e abordagens metodológicas que vem pautando as novas pesquisas, como a Guerra Fria cultural, as doutrinas de política externa soviéticas para a América Latina, as ações de propaganda e os intercâmbios comerciais.

\section{A Guerra Fria na América Latina antes de 1958}

É consenso que a mudança de eixo da Guerra Fria para a Europa e para a Ásia, entre o final dos anos 1940 e a década de 1950, relegou à América Latina e ao Brasil a um espaço mais limitado na agenda internacional norte-americana. Ainda assim, os Estados Unidos não se descuidaram do continente, impondo uma organização de países americanos sob sua tutela, a Organização dos Estados Americanos (OEA, 1948), e um tratado militar, o Tratado Interamericano de Assistência Recíproca (TIAR, 1947). Em 1954, em reunião na Cidade do México, 17 países formaram a "Comissão Permanente do Congresso para Não-intervenção soviética na América Latina", assumindo os termos da política de Segurança Hemisférica traçada pelos estrategistas estadunidenses e alimentados pelo já consolidado anticomunismo das elites latino-americanas. Em verdade, os países latino-americanos eram vistos como um território de influência "natural" dos Estados Unidos, espaço de projeção de poder da superpotência dado o "fatalismo geográfico" que fundamentava a posição geopolítica do continente na defesa do "Hemisfério Ocidental".

A prioridade da "segurança hemisférica" preventiva e do alinhamento automático deram o tom dessa fase da estratégia estadunidense para a Guerra Fria na América Latina (1947-1957), expressão da política de "contenção do comunismo", tal como havia sido

\section{CANPHLAC}


desenhada pela Doutrina Truman e pelo National Security Act ${ }^{3}$ (1947), em linhas gerais mantidos na administração Eisenhower, entre 1953-1960 (RABE, 1988). Com um mundo ainda em grande parte dominado por impérios coloniais, regimes comunistas ou capitalismos nacionais (sobretudo os europeus) ciosos de sua independência e tradição em relação às outras potências, a América Latina era um espaço de projeção natural da doutrina da Open Door Policy norte-americana, que idealizava um mundo livre-cambista de livre fluxo de bens e capital, que obviamente favoreceria a economia mais forte, industrializada e exportadora de capitais, como os Estados Unidos (LANGLEY, 1990; MALAN, 1995; SEWELL, 2008, MUNHOZ, 2017). Eisenhower manteve o discurso de "trade not aid", entendendo que a "ajuda" norte-americana deveria ser compreendida como o incremento natural do comércio bilateral entre os diversos países latinoamericanos a partir de uma política de abertura de mercados que nem sempre tinha contrapartida dos Estados Unidos.

Até aproximadamente 1957, ainda que houvesse partidos comunistas mais ou menos importantes em cada contexto nacional, o governo americano e sua comunidade de inteligência e diplomacia acreditavam que a América Latina não sofria nenhum assédio mais grave por parte da suposta "política expansionista” da URSS, embora toda vigilância fosse pouca, e que a combinação de sistemas políticos oligárquicos e ditaduras militares autoritárias seria o suficiente para controlar os comunistas, ultranacionalistas e agitadores de todo tipo.

Nessa fase, a preocupação dos norte-americanos era com líderes nacionalistas e reformistas com capacidade de mobilização de massas e cujo principal apelo simbólico residisse na retórica anti-imperialista. A se julgar pelos inúmeros documentos da CIA e do $\mathrm{NSC}^{4}$ produzidos entre fins dos anos 1940 e fins dos anos 1950, a convergência de lideranças nacionalistas e agrupamentos comunistas poderia representar uma ameaça,

\footnotetext{
${ }^{3}$ O National Security Act, aprovado pelo Senado em julho de 1947 e efetivado em setembro do mesmo ano, reorganizou as estruturas militares e de inteligência dos Estados Unidos em face da Guerra Fria, articulando a defesa interna ("segurança nacional”) e a proatividade geopolítica calcada na "defesa hemisférica" contra o "avanço do comunismo". Entre os seus subprodutos podemos citar a criação da CIA e do Conselho de Segurança Nacional, think tank oficial das políticas norte-americanas durante a Guerra Fria.

${ }^{4}$ O National Security Council foi criado em setembro de 1947, reunindo a alta cúpula do governo estadunidense e altos comandantes militares, acrescido de um conselheiro de Segurança Nacional. O Conselho foi criado para coordenar as atividades diplomáticas e militares tendo em vista as relações tensas com a União Soviética, exercendo particular importância na política global de "contenção do comunismo".
}

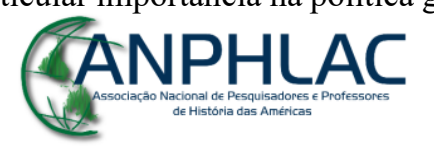


sobretudo quando conseguiam se "infiltrar" em governos de corte nacionalista, como em Vargas no Brasil, Juan Domingo Peron na Argentina e Jacob Arbenz, na Guatemala. Não por acaso, os três governos eram duramente criticados pelos conservadores anticomunistas e foram derrubados por golpes de Estado, em 1954 e 1955. No caso de Arbenz, é mais do que comprovada a participação direta dos serviços de inteligência norte-americanos.

Um memorando endereçado ao Diretor de Inteligência da CIA, de outubro de 1953, declarava que poucos partidos comunistas na América Latina tinham estrutura organizacional semelhante ao seu similar soviético, permanecendo "pequenos, sectários e politicamente confinados". Os únicos países nos quais a atividade comunista deveria ser objeto de atenção eram a Guatemala, a Bolívia, o Brasil (que possua o maior PC da América Latina, conforme o documento) e a Guiana Inglesa. Mas por serem vistos como uma "seção" de um "partido comunista mundial" (Sic!), essa aparente fragilidade dos PCs nacionais não poderia ser completamente subestimada. Em países onde os PCs não representavam uma preocupação naquele contexto, as atividades comunistas junto a setores estratégicos da economia (no caso da Venezuela) ou as relações com a URSS nos casos do México e da Argentina deveriam ser acompanhadas com atenção.

Já o briefing do Conselho de Segurança Nacional (NSC) dos Estados Unidos de fevereiro de 1954 reafirmava a preocupação especial com os casos do Brasil e da Guatemala, mas alertava que apenas na República Dominicana e no Haiti a atividade comunista era "insignificante". A penetração em setores intelectualizados da sociedade civil (meio estudantil, sobretudo) e no governo eram os pontos que mais preocupavam. $\mathrm{O}$ briefing citado aponta que mais de 900 latinoamericanos viajaram de maneira subsidiada para a União Soviética em 1953, sendo que 600 participaram do tradicional Festival da Juventude, sediado naquele ano em Bucareste. Para a CIA e o NSC, a atividade comunista nos países latino-americanos era parte de uma política externa soviética na direção de um expansionismo global, imaginário fundamental para justificar a contrapartida de uma política de contenção do comunismo igualmente global.

Apesar das advertências e dos termos, que poderiam variar de agência para agência, o tom geral dessa documentação não era particularmente alarmista, sugerindo que os níveis corriqueiros de vigilância policial e repressão política em cada país dariam conta da contenção dos comunistas latino-americanos. Para os casos mais graves, o

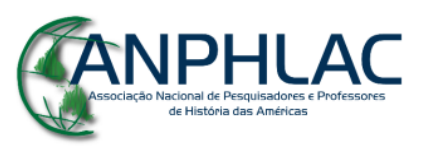


melhor caminho era a intervenção militar, via OEA. Em comum, a visão do império comunista expansionista ameaçando as bases da "civilização cristã" e do "mundo livre".

Por outro lado, ainda que o comunismo não fosse um perigo real e imediato, a incorporação da histeria anticomunista pelas elites conservadoras latino-americanas era bastante apropriada para manter as estruturas autoritárias e oligárquicas que marcavam a política de vários países, impedindo qualquer política de inclusão das massas pauperizadas ou de modernização das bases econômicas em grande parte calcadas na agroexportação de produtos primários.

De todo modo, o ano de 1958 é considerado por alguns autores um ano de inflexões para a política norte-americana em relação à América Latina (ZANISHER \& WEIS, 1989). O impacto da "desastrosa” excursão do vice-presidente Richard Nixon por alguns países da América do Sul em maio de 1958, a proposta de uma nova geopolítica e o apoio financeiro para o continente contidos na Operação Pan-Americana de Juscelino Kubitschek (inspirada no Plano Marshall), combinados ao crescimento do nacionalismo econômico em 1959 e à aproximação, ainda que tímida e limitada a trocas comerciais com a União Soviética demonstravam que o continente hispano falante e seu "gigante" que falava português desejavam ser algo além de um "quintal” estadunidense.

\section{O Pearl Harbour Diplomático}

A viagem de Nixon pelo continente, que deveria ser de naturezaprotocolar a fim de sinalizar e reiterar as alianças orgânicas e identidades entre os Estados Unidos e a América Latina, acabou se transformando em um episódio de conflitos graves, que ficou conhecido como "Pearl Harbour diplomático" (ZANISHER \& WEIS, 1989).

Era notória a importância do continente latino-americano na política de contenção ao comunismo no hemisfério, o que, como vimos, passava pela contenção dos ímpetos nacionalistas que começavam a se fortalecer em parte das elites latino-americanas. Ao mesmo tempo, a retórica dos projetos nacionalistas destacava as dificuldades comerciais que envolviam os países latinoamericanos, basicamente exportadores de produtos primários submetidos às políticas de comércio exterior dos Estados Unidos. O rebaixamento dos preços dos produtos primários e a relutância norte-americana em apoiar o desenvolvimento econômico por meio de ajudas financeiras de grande monta era fator

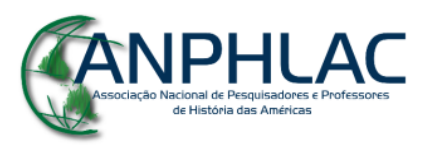


de tensão. Eisenhower enviou Nixon para apaziguar tais tensões em uma tentativa de manter portas abertas para "diálogo" com as lideranças latino-americanas. O que seria uma espécie de "missão de boa vontade", se transformou no mais sério incidente envolvendo um alto dignatário do governo norte-americano.

A viagem começou bem em fins de abril pelo Uruguai e pela Argentina. Em Montevideo algumas dezenas de estudantes protestaram contra Nixon, mas no geral ele foi bem recebido quando visitou a tradicional Universidade de La Republica. Na Argentina, Nixon compareceu à posse de Arturo Frondizi, que assumia o governo propondo uma via moderada de desenvolvimentismo e modernização para o país.

Em Lima houve os primeiros confrontos mais sérios entre a comitiva de Nixon e os estudantes peruanos quando o vice-presidente tentou conversar com os jovens na Universidade. Na volta para o hotel, houve outros enfrentamentos com a multidão que protestava, entretanto, o confronto mais sério teve lugar em Caracas, última parada do Latin American tour. O apoio norte-americano ao ditador recém-deposto Marcos PérezJiménez, concedendo-lhe inclusive asilo político por ocasião de sua queda diante de um levante popular criara um clima de animosidade para a visita. Havia rumores de atentado contra Nixon, o que levou a CIA a sugerir o cancelamento da viagem. O Partido Comunista Venezuelano, ator importante na queda de Jimenez, galvanizou o sentimento antiamericano que dominava o país.

Os problemas começaram ainda no trajeto entre o aeroporto e o Panteão Nacional, onde teria lugar uma cerimônia protocolar em homenagem a Simon Bolívar. A comitiva de carros ficou parada em um engarrafamento e a multidão cercou o carro que levava Nixon. Além de jogar pedras e bater contra o veículo, houve uma tentativa de virar o carro com Nixon dentro. Tanto os registros da imprensa quanto dos serviços de segurança apontam que a polícia venezuelana não agiu para conter os manifestantes. A segurança de Nixon ficou na mão de doze agentes do serviço secreto, que chegaram a sacar suas pistolas para atirar contra a multidão. Apesar de alguns feridos por estilhaços de vidro na comitiva, o carro de Nixon conseguiu furar o cerco da multidão.

Nixon se refugiou na embaixada norte-americana, que ficou cercada por forças de segurança, sendo retirado do país sete horas antes do previsto sob forte esquema de segurança.

\section{CANPHLAC}


Os episódios violentos no tour latino-americano de Nixon são vistos como a primeira tomada de consciência do antiamericanismo e "yankeefobia" dos policimakers da política externa dos Estados Unidos (MCPHERSON, 2003). Não por acaso, logo depois dos incidentes, Juscelino Kubitscheck tentou capitalizar o evento, propondo um outro nível de cooperação entre os Estados Unidos e a América Latina por meio da Operação Pan-Americana.

\section{A nova diplomacia soviética e a América Latina: A Era Krushev}

O outro polo da geopolítica da Guerra Fria também passava por mudanças importantes, não apenas na sua política interna, mas também na política externa. A "Era Krushev", cuja liderança junto ao Partido Comunista e ao Estado se consolidara em 1956, depois de alguns anos de conflitos e incertezas, marcou mudanças importantes na ação geopolítica da União Soviética.

Entre 1956 e 1962, a superpotência comunista viveu um momento peculiar na sua trajetória histórica, marcada pelo "degelo" e pela tese da "coexistência pacífica" com o Ocidente. Aquela conjuntura propiciou a emergência de uma União Soviética mais aberta às relações comerciais, culturais e políticas com o "Terceiro Mundo", substituindo a prioridade dada ao Leste Europeu e à Ásia nos primeiros anos da Guerra Fria sob a batuta de Stalin, o que fazia com que a América Latina entrasse no radar dos dirigentes soviéticos (MILLER, 1989; BLASIER, 1988; CHESTON et al, 1974).

A diplomacia de Krushev tentava conciliar dois princípios aparentemente contraditórios: um novo "internacionalismo revolucionário anticolonial” e a "coexistência pacífica" com o bloco ocidental capitalista. Conforme Arno Westad, essa aproximação visava menos à exploração e sujeição política, no sentido consagrado pelo imperialismo ocidental-capitalista, e mais a uma política de controle (inclusive das esquerdas nacionais de cada país) e promoção das relações comerciais entre os Estados (WESTAD, 2006; WESTAD, 2000a). Tal estratégia visava romper, pelas periferias, a política de isolamento imposta de dentro pelo estalinismo tardio (1947-1953) e de fora pela política de contenção do comunismo norte-americana.

As dificuldades da União Soviética com a Polônia e a Hungria, entre 1955 e 1956, foram compensadas pela inabilidade dos aliados ocidentais no trato da crise de Suez,

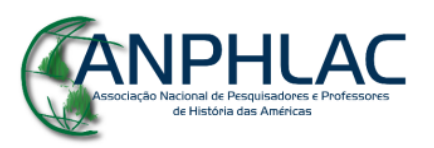


quando franceses, ingleses e israelenses, mesmo sob crítica dos Estados Unidos, ocuparam o famoso Canal (JUDT, 2007). Esse episódio, lastreado por uma visão de mundo abertamente colonialista por parte das duas potências europeias, reforçou ainda mais a legitimidade do nacionalismo dos países asiáticos e africanos que lutavam contra o colonialismo europeu. Na nova ordem mundial do pós-Guerra, o velho colonialismo era condenado, embora a ação das Nações Unidas fosse limitada tanto pelo poder de veto de Inglaterra e França quanto pela delicada posição dos Estados Unidos, crítico do velho colonialismo europeu, mas fiador da defesa do Ocidente contra o Comunismo. A própria emergência do conceito de Terceiro Mundo, entre o nacionalismo e o não-alinhamento aos dois blocos que dividiam o mundo naquela década, está ligada a esta configuração internacional. Nesse jogo, a União Soviética conseguiu avançar suas peças, ocupando novos espaços no xadrez internacional.

O apoio de Krushev a Gamal Abdel Nasser, presidente do Egito que nacionalizou o Canal de Suez, foi o batismo da nova política externa soviética para o Terceiro Mundo. Logo, a América Latina entraria nessa agenda diplomática soviética, ainda que a situação política e geopolítica dos países latino-americanos fosse bem diferente daquela do Oriente Médio. No caso da América Latina, a presença histórica dos Estados Unidos, a presença de Estados nacionais independentes estruturados havia mais de um século e o anticomunismo orgânico de suas elites nacionais representavam desafios à estratégia soviética de ocupar novos espaços internacionais. Em princípio, a América Latina não era um território propriamente em disputa.

Por outro lado, a emergência de um nacionalismo reformista no pós-Guerra, questionando a dominação das oligárquicas agrárias era uma janela de oportunidades que se abria a novos parceiros, para além dos Estados Unidos, que demonstravam pouca sensibilidade e tolerância com tais novas demandas. Essa nova política internacional em torno da América Latina foi incrementada a partir de 1957 como resultado de uma nova perspectiva soviética para o "Terceiro Mundo" (GOLDHAMER, 1972; BLASIER, 1987; CHESTON et al., 1974). Em linhas gerais, mais que defender o comunismo, os soviéticos passaram a defender a "via não capitalista para o desenvolvimento", slogan um tanto vago, mas que encontrou particular ressonância nas lideranças reformistas e nacionalistas latino-americanas.

\section{CANPHLAC}


O telegrama de "ano-novo" de Nikita Krushev ao presidente JK no fim de 1957 era um dos indícios dessa nova política para a América Latina, consumada com o primeiro acordo comercial mais significativo com o Brasil, em dezembro de 19595. Tal aproximação, ainda que limitada ao comércio, não passou despercebida pelos americanos, o que provocou até um pedido de "esclarecimentos" por parte do Departamento de Estado e seu secretário linha-dura, John Foster Dulles (BOJUNGA, 2002). Na ótica norteamericana, o nacionalismo "radical" dos latino-americanos era a porta de entrada para a influência comunista e a agitação social. Se essa preocupação já aparecia em documentos do início dos anos 1950, ela se torna mais nítida a partir de 1959. A preocupação com os nacionalistas encontrava muitos aliados internos nos diversos países latino-americanos, fossem as velhas elites oligárquicas liberais e livre-cambistas, fossem militares autoritários, antirreformistas e elitistas.

Algumas movimentações no lado soviético demonstram a importância crescente da América Latina. Em novembro de 1959, o vice-Premier, Anastas Mikoyan foi o primeiro alto dirigente soviético a visitar o México, abrindo a Exposição Soviética e permanecendo 10 dias em visita oficial (MIKOYAN, 1995: 27).

Um relatório soviético de 1960 captou essa "janela de oportunidades" que se abrira ${ }^{6}$ :

The stagnant nature of the economy and foreign trade of Latin America, on the one hand, and the constant improvement of the socialist economy, on the other, have demonstrated that the lack of economic ties with the socialist countries has caused harm to only the countries of Latin America. Artificially-created trade barriers have led to the accumulation and even the destruction of unsaleable export production with an acute hortage of imported manufactured and consumer goods. Consequently not only the workers, but also the broad circles of the national bourgeoisie realize that in the current conditions the underdeveloped countries cannot be isolated from the socialist camp. This has special importance for the countries striving to create an independentEconomy.

Apesar do tom retórico, misturando a análise objetiva da conjuntura com um fraseado cheio de jargões, o Relatório claramente intui que o nacionalismo econômico e as condições de comércio impostas pelos Estados Unidos (rebaixamento dos preços de

\footnotetext{
${ }^{5}$ O Tratado Comercial entre Brasil e URSS foi assinado em dezembro de 1959, tratando-se do primeiro grande tratado comercial entre os dois países.

6 "Soviet Report, 'Economic Cooperation between Latin America and the Countries of the Socialist Camp'," 1960, History and Public Policy Program Digital Archive, Archive of the Russian Academy of Sciences, f. 1798 op. 1 d. 88 1l. 124-136. Obtained for CWIHP by Vanni Pettina and translated by Gary Goldberg. http://digitalarchive.wilsoncenter.org/document/122358
}

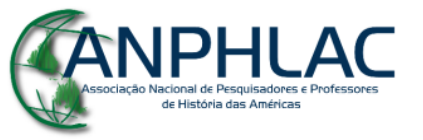


bens primários, exigência de pagamento em divisas fortes e barreiras que impediam a indústria local) estavam em choque na América Latina.

O ano de 1960 foi marcado por um conjunto de atitudes claramente voltadas a consagrar o novo "internacionalismo revolucionário anti-imperialista" dos soviéticos na direção do Terceiro Mundo, ao mesmo tempo em que procuravam afirmar sua hegemonia na esquerda mundial. Naquele ano foi formulado o conceito de "revolução democrática", categoria ideológica que norteava o apoio soviético no Terceiro Mundo, tendo como modelos Cuba e Argélia. Em setembro, Krushev proferiu seu famoso discurso anticolonialista na Assembleia Geral das Nações Unidas e em novembro do mesmo ano houve em Moscou o Congresso Mundial dos Partidos Operários e Comunistas, do qual participaram 20 países da América Latina. Na esteira da Revolução Cubana, ainda com rosto indefinido, mas claramente antiamericano, Krushev declarava que a "Doutrina Monroe estava morta".

Antes dessas contundentes sinalizações diplomáticas na virada dos anos 1950 para a década seguinte, a América Latina já estava no radar soviético, ainda que os sinais fossem fracos e sujeitos às contradições da política externa soviética, na qual se misturavam elementos ideológicos e diplomáticos, nem sempre confluentes e coerentes (MAJDANIK, 1995). Vale ressaltar que esse "duplo caminho" da diplomacia soviética ideológico e político-pragmático - nunca foi muito bem resolvido e harmonizado, tendo estado sujeito às delicadas vicissitudes políticas da luta pelo poder no Kremlin. Mesmo assim, a presença da União Soviética na América Latina, ainda que no plano das trocas e intercâmbios culturais, era potencializada pelo anticomunismo e pela preocupação geopolítica norte-americana.

Até 1954, apenas Argentina e México eram países que interessavam à diplomacia soviética. A partir de Krushev, a linha de ação ideológica (visando manter o controle dos Partidos Comunistas na linha do anti-dogmatismo, anti-revisionismo e contrários à "linha chinesa", a partir de 1959) e a aproximação diplomática estiveram mais próximas (MAJDANIK, 1995: 14). Para Kiva Maidanik, entre 1960 e 1963, o nível ideológico predominou nas relações entre URSS e América Latina, mantendo-se em alguns aspectos e de maneira errática e enfraquecida até 1973. Com a derrota da Unidade Popular, as relações voltaram a ser pautadas no pragmatismo e nas relações frias entre os Estados e pactos de comércio (MAJDANIK, 1995: 15). Assim, a "Era Krushev" foi o ápice da

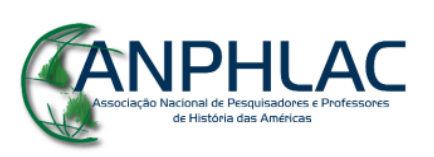


aproximação entre a URSS e a América Latina, marcada por uma linha de ação que não sobreviveu à queda do dirigente e aos conflitos entre a União Soviética e a política externa cubana em apoio às guerrilhas no continente.

\section{Diplomacia Cultural da União Soviética para a América Latina}

A diplomacia cultural e as conexões intelectuais e culturais estabelecidas por atores não-estatais (por exemplo, os Partidos Comunistas e as organizações intelectuais progressistas) foram fundamentais para a estratégia soviética de aproximação com a América Latina. Em grande parte, arrisco dizer que ela se antecipou à diplomacia política e econômica, preparando o terreno para o reconhecimento diplomático e a assinatura de tratados comerciais a partir da segunda metade dos anos 1950.

Em 1955, foi aberta a primeira grande exposição soviética na América Latina, na cidade de Buenos Aires, com mais de 1 milhão de visitantes. No mesmo ano, Nicolai Bulganin, chanceler, declara que o interesse soviético na América Latina estava concentrado em estabelecer intercâmbios políticos, culturais e econômicos, "sem interferência em assuntos internos" (Jornal Visión, apud RUPRECHT, 2012: 35).

A esta seguiram-se outras três grandes exposições: México, 1959, Havana, 1960 e Rio de Janeiro, 1962. Várias associações culturais pró-soviéticas se espalharam pelo continente, sendo acompanhadas de perto pelos aparatos de propaganda do Estado soviético. Um relatório da CIA de 1961 revelava a importância das associações culturais para a nova diplomacia soviética a partir do final dos anos 1950 (Information Report, CIA, 24/outubro/1961). Ao todo, a aparato, coordenado até 1959 pela VOKS (Associação PanSoviética de Relações Culturais com o Exterior) e depois disso pela SSOD (União das Sociedades de Amizade), reunia 33 organizações e 10 mil "voluntários", e era herdeiro das associações criadas ainda nos anos 1920. A partir de 1956, a estratégia dessas associações era se abrir para simpatizantes não-comunistas nos diversos países em que atuavam. Na América Latina, em 1959, havia 7 associações específicas (duas no Uruguai, duas no México, além do Brasil, Cuba e Venezuela). Além disso, os países comunistas da órbita soviética (Polônia, Tchecoslováquia e Romênia, sobretudo), tinham associações similares em quase todos os países latino-americanos, sendo que frequentemente

\section{CANPHLAC}


replicavam a diplomacia cultural soviética. Em 1959, foi fundada a Associação de Amizade Soviético-Latino-Americana, que em 1964 reunia 14 países.

O VI Festival Mundial da Juventude de Moscou, em 1957, foi um marco na diplomacia cultural soviética com a participação de mais de 800 latino americanos (RUPRECHT, 2012: 75). Em 1960, havia cerca de 20 publicações soviéticas em espanhol ou português, com mais de 130 horas por semana de emissões radiofônicas. Havia até uma rádio especialmente voltada à América Latina, a Rádio Progresso. Os festivais de filmes soviéticos foram particularmente importantes a partir de 1957, inclusive como prova de uma nova era de liberdade de criação, conhecida como a "cultura do degelo" (conforme expressão do escritor Ilya Ehrenburg).

Ainda que reconhecessem a região como área de influência direta dos Estados Unidos, os soviéticos tentaram se aproveitar do nacionalismo econômico, das conexões culturais não-estatais e da tentativa de abertura geopolítica do Brasil e de outros países para se fazerem presentes para além dos pequenos círculos de simpatizantes comunistas de sempre. Para tal, os soviéticos tentaram ampliar seus laços de comércio e seu softpower junto aos países latino-americanos, sobretudo Argentina, Brasil e Uruguai, além de aprofundar suas boas relações históricas com o México. Foram incrementadas as visitas parlamentares, os acordos comerciais, intelectuais e científicos, as exposições de ciência, cultura e tecnologia. Eventos ainda poucos estudados, como a excursão do cosmonauta Yuri Gagarin ao continente (1961), apelidado de Colombo do Cosmos, o acordo comercial brasileiro-soviético de 1959, a importância do Brasil e da América Latina hispânica na propaganda e na imprensa soviética do início dos anos 1960 ou as excursões de músicos e bailarinos soviéticos pelo continente (Balé Bolshoi em Montevideo, Buenos Aires, Rio de Janeiro, 1958) marcam o incremento bem sucedido do soft power da superpotência comunista (RUPPRECHT, 2012).

Esta não foi uma via de mão única, pois a presença da América Latina na sociedade e na cultura soviética não era insignificante, com as constantes excursões artísticas de músicos latino-americanos e a presença da literatura latino-americana na cena cultural soviética a partir de 1959, quando foi publicado no país um dos livros iniciais do realismo mágico latinoamericano, Doña Barbara, de Romulo Gallegos.

Um dos aspectos que a pesquisa sobre o tema deve aprofundar é o impacto efetivo dessa política cultural soviética aliada à sistemática política cultural dos partidos

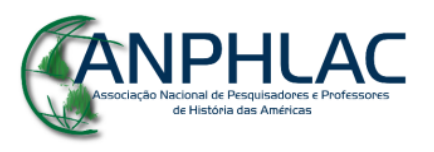


comunistas para além das relações Estado-Estado, tornando-se um elemento importante em muitos grupos da sociedade civil para além dos comunistas militantes. Ainda que a diplomacia cultural soviética não tenha conseguido romper o anti-sovietismo das elites latino-americanas mais conservadoras, foi um importante capítulo da Guerra Fria cultural, sobretudo entre fins dos anos 1950 e início dos anos 1960.

\section{Quanto mais quente pior: a crise do novo internacionalismo soviético na América Latina}

Apesar da cautela, houve um esforço para afirmar os interesses soviéticos no Brasil do período, sendo que no final do governo João Goulart, a possibilidade de um afastamento do gigante sul-americano com os Estados Unidos abria novas e inusitadas possibilidades para a diplomacia soviética. Entretanto, não podemos cair na tese do “expansionismo soviético" sem reflexão crítica sobre seus limites. O avanço da política externa e da diplomacia cultural dos soviéticos no continente ainda se dava pela lógica de “abertura de oportunidades" e de movimentos tímidos dentro do quintal da superpotência inimiga, bem como se movimentavam entre o princípio ideológico (a expansão do comunismo com base no "internacionalismo revolucionário") e o pragmatismo das relações Estado-Estado. Mesmo a aliança cubano-soviética não chegou a ser a afirmação inequívoca da geopolítica soviética no continente, pois logo depois de 1962 as relações entre os dois países esfriaram, normalizando-se somente após 1970 com o recuo do castrismo no apoio às guerrilhas continentais. O fato é que para os soviéticos não interessava a elevação das tensões com os Estados Unidos na América Latina, e a resolução da Crise dos Mísseis foi uma sinalização neste sentido. Tratava-se mais de uma movimentação tática para criar uma agenda antiamericana no continente do que propriamente uma intervenção direta ou indireta em processos revolucionários e a criação de novos países-satélites. A hesitação dos partidos comunistas latino-americanos na organização de movimentos armados era a contraface dessa geopolítica da URSS, particularmente forte após a queda de Krushev, em 1964.

Por outro lado, não era possível deixar de atuar no continente historicamente tutelado pelos norte-americanos, ainda que as intervenções para mudar os regimes locais não fossem contundentes. As próprias elites nacionalistas e desenvolvimentistas da América Latina acenavam para novas relações com os soviéticos, para além de qualquer

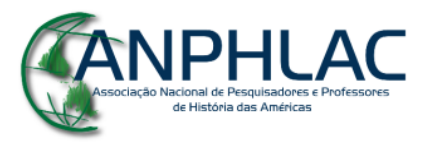


apoio ao comunismo. Em verdade, a política cultural da URSS para a América Latina procurava sutilmente dissociar a imagem positiva da União Soviética de qualquer propaganda do comunismo como ideologia (RUPRECHT, 2012). No plano da propaganda, mais que defender o comunismo como ideologia, os soviéticos procuravam vender a imagem de um país pacífico, solidário, modelo de desenvolvimento econômico e social sob a marca do planejamento estatal. Para uma América Latina marcada pela busca de um caminho próprio para o desenvolvimento, tais chamadas tinham ressonância no imaginário de uma parte das elites, democráticas, nacionalistas e reformistas. Para estas, longe de ser uma ameaça, a União Soviética era vista como contrapeso ao jugo americano e seus aliados internos, visão que ia de encontro às elites conservadoras e liberais.

Como resposta ao nacionalismo crescente e à nova percepção da Guerra Fria no continente, os Estados Unidos, sob a administração Kennedy, lançaram uma nova política para a América Latina, chamada de "Aliança pelo Progresso", em março de 1961, sempre pensada na chave da contenção do comunismo (SILVA, 2008). As políticas de formação de uma nova intelectualidade, pautada pelo antitotalitarismo e por um reformismo moderado, foi ainda mais valorizada pelas agências de intercâmbio cultural norteamericanas, muitas delas recebendo dinheiro clandestino da CIA (CANCELLI, 2005; CANCELLI, 2015). Contando com o envolvimento de várias agências oficiais, tal política visava combinar maior presença econômica, cultural e humanitária dos Estados Unidos em um grande esforço coordenado e bilateral para modernizar as arcaicas relações sociais e econômicas do continente latinoamericano. Ainda assim, as tensões com o governo brasileiro e as pressões para preservar os "interesses norte-americanos" não diminuíram (FICO, 2008; LEACOCK, 1990). Por outro lado, a "Aliança para o Progresso" não pode nem de longe ser confundida com um Plano Marshall para a América Latina, seja em termos de montante financeiro disponibilizado ou em termos de processo decisório envolvendo alocação de recursos, sempre sob controle norte-americano (LOUREIRO, 2017).

A crise cubana aliada ao nacionalismo reformista crescente, defendida pelo governo brasileiro, acirrou a disputa geopolítica pelo continente entre as duas superpotências. Muitos países latino-americanos tentaram tirar vantagem da crise, reposicionando-se em relação à tradicional assimetria em relação aos Estados Unidos (KELLER, 2015). Além disso, o Brasil desenvolvia uma nova doutrina de ação

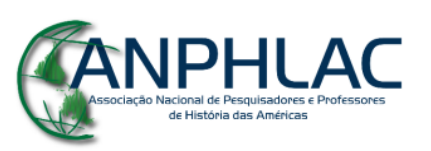


diplomática, conhecida como Política Externa Independente, afastando-se, ao menos no discurso e nas movimentações protocolares do jogo diplomático, da tradicional aliança estratégica com os Estados Unidos, lançada no começo do período republicano, em fins do século XIX (TOPIK, 2009).

Em janeiro de 1962, a PEI se fez ouvir na Conferência de Punta del Este (AVILA, 2001). A reunião da OEA foi convocada, a pedido da Colômbia (instada pelo governo norte-americano) para avaliar a expulsão de Cuba da OEA, por "ameaçar a paz e independência política dos Estados americanos". Durante a conferência vários chanceleres, liderados pelo brasileiro Francisco San Tiago Dantas, foram contra a medida extrema, alegando, com habilidade, que a exclusão de Cuba da comunidade panamericana e a manutenção do embargo comercial americano só aumentaria a influência soviética na região. Ao final, ainda que o Brasil e outros países (Argentina, México, Chile, Bolívia e Equador) tenham se abstido da votação pela expulsão de Cuba, tal opção acabou prevalecendo.

A “crise dos mísseis", provocada pela instalação de projéteis soviéticos na ilha caribenha, foi o ponto alto das tensões da Guerra Fria, não apenas em nível continental, mas mundial. $\mathrm{O}$ mundo esteve à beira de um conflito nuclear e, se a diplomacia entre os líderes das superpotências fez valer o bom-senso, a Guerra Fria se intensificou no continente. Cuba se afirmou como "farol" socialista, embora as relações com os soviéticos depois da crise tivessem ficado sensivelmente abaladas, demarcando um processo de aproximação e afastamento entre os dois países que duraria até o começo da década de 1970, quando a ilha se alinhou efetivamente com a política externa soviética.

O episódio remodelou não apenas as relações dos Estados Unidos com o Continente, mas também gerou impacto ao outro lado. A própria liderança de Nikita Krushev e sua política proativa para o Terceiro Mundo foram seriamente abaladas com o desfecho do episódio dos mísseis, alimentando seus inimigos da "oligarquia partidária" do PCUS e da KGB que viam o "novo internacionalismo" como um jogo perigoso para a segurança soviética, e culminou na deposição de Krushev em 1964 (RUBOK \& PLESHAKOV, 1996). Sergo Mikoyan destaca as tensões geradas pela política externa de Krushev e o novo arranjo geopolítico depois da queda do Secretário-Geral soviético (MIKOYAN, 1995: 30):

One could observe a strange phenomenon in Moscow; there were some officials who thought about Latin America at large just like

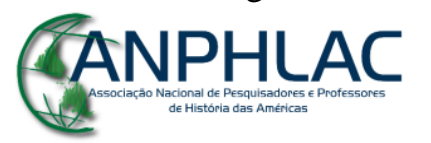


their counterparts in Washington: no more Cubas! (...) After the change of command in the Kremlin because of Nikita Khrushchev's retirement in October 1964, several factors appeared from both sides to cool Soviet-Cuban relations. In Moscow, it was the end of "romantic" approach in the Kremlin, there were anti-guerrilla feelings and general attempts by the new leadership to re-evaluate Khrushchev's foreign policy. In Cuba, there was the growing stress on the guerrillas, a different attitude to liberal governments in Latin America, and a Cuban unwillingness to submit to changes in Moscow's foreign policy, diplomacy, and strategic vision as a whole.

Contraditoriamente, o refluxo do internacionalismo revolucionário sob Leonid Brezhnev e a implantação de ditaduras militares de extrema-direita na América Latina não significaram o fim das relações com a União Soviética. Em meados dos anos 1970, ditaduras anticomunistas como o Brasil e a Argentina incrementaram as relações diplomáticas e comerciais com a superpotência comunista, que aceitou pragmaticamente o seu lugar no jogo geopolítico de cartas marcadas.

\section{Considerações finais}

O estudo das relações entre URSS e América Latina deve ir além das relações interestatais, embora tal aspecto não possa ser minimizado, até pelo fato de que ainda é relativamente pouco estudado. Essa relação envolve um complexo jogo de influências e contrainfluências culturais e ideológicas que perpassam as diversas sociedades civis envolvidas, e que acabaram por gerar representações e impor filtros para a própria historiografia (RUPRECHT, 2012). Há várias armadilhas para o pesquisador, começando pela necessidade de lidar criticamente com as representações e imagens pré-concebidas pelos estudiosos mais influentes e ligados aos think thank da política internacional, quase sempre pendendo para uma visão maniqueísta de geopolítica, a começar pelo clássico John Gaddis (GADDIS, 2006; GADDIS, 1997). Nessa linha historiográfica mais tradicional, a América Latina e a União Soviética foram definidas a partir de uma imagem liminar do Ocidente, envolvendo categorias analíticas problemáticas elaboradas a partir não apenas de uma perspectiva acadêmica distanciada, mas também dentro de um conjunto de valores ideológicos que norteou a luta política da época, tais como: periferia, atraso, totalitarismo, expansionismo, terceiromundismo, nacionalismo, populismo. Muitas dessas categorias sofreram fortes revisões acadêmicas ao longo das últimas décadas, o

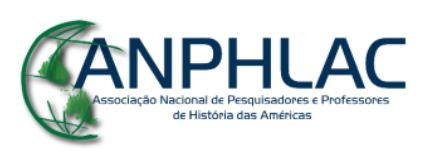


que tem exigido um novo olhar sobre a própria história global durante a Guerra Fria, deixando de ver a América Latina e o Terceiro Mundo como meros reflexos dos influxos geopolíticos das superpotências e sua política de blocos homogêneos (WESTAD, 2006; GILBERT \& SPENSER, 2008).

Por outro lado, a sobrevivência cultural e simbólica das representações geradas durante a Guerra Fria na América Latina, constantemente mobilizadas na luta políticoideológica contemporânea, aponta para a importância de se estudar a época para além do sistema internacional ou da geopolítica de Estado. A Guerra Fria e suas representações marcaram o imaginário e os valores em disputa nas sociedades latino-americanas em sua luta pela emancipação nacional e contra as mazelas e desigualdades sociais. Um ponto que ainda precisa ser aprofundado é a importância das representações geradas no contexto da Guerra Fria para atualizar os valores elitistas e oligárquicos das elites políticas latinoamericanas, fornecendo o mote do "bom combate" contra o totalitarismo, por exemplo. Até hoje esse tema serve como amalgama simbólico de grupos conservadores de direita, embora seja completamente extemporâneo. As relações internacionais forjadas à época, seja com os Estados Unidos, a União Soviética ou Cuba, em grande parte forneceram bases simbólicas para tal imaginário, seja este conservador ou progressista. Mesmo com o fim da União Soviética, certos discursos conservadores ainda se mantêm presos à lógica bipolar gerada nos anos 1950 e 1960, como demonstra o "antirussismo" ainda vigente no Ocidente. À esquerda, em que pese o esforço de autocrítica produzido pela derrota dos projetos de luta armada dos anos 1960 e 1970, as representações do "imperialismo" ainda fornecem representações importantes para a construção de um sentimento de pertencimento de agrupamentos políticos. Embora, neste caso, devemos reconhecer que o "imperialismo" pode ser algo mais do que um fantasma à disposição de retóricas extemporâneas.

Todo esse aparente anacronismo, ou seja, a sobrevivência cultural do vocabulário e das representações da Guerra Fria na América Latina do século XXI, talvez não seja apenas manifestação superestrutural vazia ou mera pantomima das nossas lideranças políticas sem projeto para os problemas atuais. Talvez ainda expressem sintomas de uma agenda de inclusão social sempre adiada e das assimetrias geopolíticas efetivas que ain da desafiam as realidades nacionais do continente.

\section{CANPHLAC}




\section{Referências Bibliográficas}

AVILA, Carlos. A conferência de Punta del Este: um estudo da VIII reunião de consulta de ministros das relações exteriores das Américas (1962). In: $3^{\circ}$ ENCONTRO NACIONAL ABRI, 3, 2001, São Paulo. Proceedings online. Assosciação Brasileira de Relações Internacionais Instituto de Relações Internacionais - USP, Disponível em: <http://www.proceedings.scielo.br/scielo.php?script=sci_arttext\&pid=MSC0000000122 011000100041\&lng=en\&nrm=abn>. Acesso em 28/2/ 2019.

BAPTISTA Júnior, Roberto. Anti-sovietismo: reflexos e práticas compartilhadas de repressão no sistema interamericano (1945-1964). Doutorado em História, UNICAMP, Campinas, 2005

BLASIER Cole The Giant's Rival: The USSR and Latin America, Pittsburg, University of Pittsburgh Press, 1987

BOJUNGA, Claudio. JK: o artista do impossível. Rio de Janeiro, Objetiva, 2010

CANCELLI, Elizabeth. Intelectualidade e poder: inconformidade na Guerra Fria. ArtCultura (UFU), Uberlãndia, v. 9, n. jul-dez, p. 111-118, 2005.

CANCELLI, Elizabeth. O Ilari e a guerra cultural: a construção de agendas intelectuais na América Latina. ArtCultura (UFU), v. 17, p. 13-45, 2015.

CHESTON T. Stephen, LOEFFKE Bernard. Aspects of Soviet Policy Toward Latin America. Nova York, MSS Information Corporation, 1974

COELHO, Anelise Suzane Fernandes. Operação PB/Success: a intervenção secreta da CIA na Guatemala e seus impactos em um contexto de Guerra Fria. Mestrado em História, UFMG, Belo Horizonte, 2012

COMBAT, Flávio Alves. A historiografia sobre a Guerra Fria e os limites do PósRevisionismo. Doutorado em História Comparada Instituição de Ensino, UFRJ, Rio de Janeiro, 2012

DOMINGUEZ, E. (ed). The Soviet Union's Latin American Policy. Goteborg Universiteit, 1995

FICKER, Sandra. Mundial, transnacional, global: um ejercicio de clarificación conceptual de los estúdios globales. Almanack, Guarulhos, ago/2015, disponível em http://www.almanack.unifesp.br/index.php/almanack/article/view/1291 (acesso em 20/2/2019)

\section{GANPHLAC}


FICO, Carlos. O grande irmão. Da operação Brother Sam aos anos de chumbo. $O$ governo dos Estados Unidos e a Ditadura Militar Brasileira. Rio de Janeiro, Civilização Brasileira, 2008

GADDIS, J. Lewis. História da Guerra Fria. Rio de Janeiro, Nova Fronteira, 2006

GADDIS, John Lewis. We Now Know: Rethinking Cold War History. New York: Oxford University Press, 1997

GILBERT, Joseph \& SPENSER, Daniela (eds). In from the Cold: Latin America's New Encounter with the Cold War. Duke University Press Books, 2008

GILDERHUS Mark T. An Emerging Synthesis? U.S.-Latin American Relations since the Second World War. Diplomatic History 1992; 16 (3): 429-452. doi: 10.1111/j.14677709.1992.tb00516.x

GOLDHAMER Herbert. The Foreign Powers in Latin America. Princeton University Press, 1972

JUDT, Tony. Pós-Guerra: uma história da Europa desde 1945. São Paulo, Objetiva, 2007

KELLER Renata. The Latin American Missile Crisis. Diplomatic History; 39 (2): 195222, 2015. Doi: 10.1093/dh/dht134

KENWORTHY, Eldon. America/Américas: Myth in the Making of US Policy toward Latin America. University Park, Penn State University Press, 1995.

LANGLEY Lester D. The United States and Latin America in the Eisenhower Era. Diplomatic History, 14 (2): 257-264, $1990 . \quad$ doi: 10.1111/j.14677709.1990.tb00090.x

LARS, Schoultz. Beneath the United States: A History of US Policy toward Latin America. Cambridge: Harvard U. Press, 1998.

LEACOCK, Ruth. Requiem for Revolution. The United States and Brazil (1961-1969). Kent State University Press, 1990

LESSA, Antonio. C. Há cinquenta anos a Operação Pan-Americana. Revista Brasileira de Política Internacional, Brasília, 51/2, 5-7, 2008.

LOUREIRO, Felipe. Aliança para poucos: ajuda econômica norte-americana para estados brasileiros durante o governo João Goulart (1961-1964). Tese de LivreDocência, Instituto de Relações Internacionais/USP, 2017

\section{GANPHLAC}


MAJDANIK, Kiva The Ideological Aspects of Soviet Relations with Latin America In; DOMINGUEZ, E. (ed). The Soviet Union's Latin American Policy. Goteborg Universiteit, 1995. 10-25.

MCPHERSON, Alan. Yankee, No! Antiamericanism in US-Latin American relations. London, Harvard University Press, 2003

MILLER, Nicola. Soviet Relations with Latin America, Cambridge University Press, 1989

MIKOYAN, Sergo. The Soviet Union and Latin America: the Political and Strategic Domain. In DOMINGUEZ, E.(ed). The Soviet Union's Latin American Policy. Goteborg Universiteit, 1995, 26-41

MOTTA, Rodrigo Patto Sá. Em guarda contra o perigo vermelho. São Paulo, Ed. Perspectiva, 2002.

MUNHOZ, Sidnei J. Guerra Fria: um debate interpretativo. In: TEIXEIRA DA SILVA, Francisco Carlos. O século sombrio: uma história geral do século XX. Rio de Janeiro: Campus, 2004

PEDEMONT, Rafael. Una historiografia en deuda: las relaciones entre el continente latino-americano y la Union Sovietica durante la Guerra Fria. Historia Critica, 55, Bogota, Enero-Marzo, 2015, 231-254

PEREIRA, Henrique. Pan americanismo e anticomunismo: a OPA no Brasil e as origens da Aliança para o Progresso. Anais do XXVI Simpósio Nacional de História - ANPUH - São Paulo, julho 2011

RABE Stephen G. Eisenhower and Latin America: The Foreign Policy of Anticommunism . Chapel Hill, University of North Carolina Press, 1988.

RABE Stephen G. The Most Dangerous Area in the World: John F. Kennedy Confronts Communist Revolution in Latin America. Chapel Hill:University of North Carolina Press, 1999.

RODEGHERO, Carla. Capítulos da Guerra Fria: o anticomunismo brasileiro sob o olhar norte-americano (1945-1964), Tese de Doutorado em História, Porto Alegre, UFRGS, 2007

RUPPRECHT, Tobias. Socialist High Modernity and Global Stagnation. A shared history of Brazil and the Soviet Union during the Cold War. Journal of Global History, 3, p. 505528,2011

\section{CANPHLAC}


RUPPRECHT, Tobias. Soviet Internationalism after Stalin: the USSR and Latin American in the Cultural Cold War. Thesis of Doctorate, European University Institute, Florence, 2012

SEWELL Bevan; A Perfect (Free-Market) World? Economics, the Eisenhower Administration, and the Soviet Economic Offensive in Latin America. Diplomatic History, 32 (5): 841-868, 2008. doi: 10.1111/j.1467-7709.2008.00732.x

SILVA, Vicente Gil. A Aliança para o Progresso no Brasil: de propaganda anticomunista a instrumento de intervenção política (1961-1964), Mestrado em História, Porto Alegre, UFRGS, 2008

TUSK Roger R. The Impact of the Cold War on United States-Latin American Relations, 1945-1949. Diplomatic History; 1 (3): 271-284, 1977. doi: 10.1111/j.14677709.1977.tb00242.x

WEINSTEIN, Barbara. Pensando a história fora da nação: a historiografia da América Latina e o viés transnacional. Revista Eletrônica da ANPHLAC, n.14, p. 9-36, jan./jun. 2013. http://revista.anphlac.org.br/index.php/revista

WEINSTEIN, Barbara. Repensando a história das relações Estados Unidos- América Latina: de dominação política a circulação cultural?. Textura, Canoas, 8, 11-20, 2003

WESTAD Odd Arne; The New International History of the Cold War: Three (Possible)Paradigms. Diplomatic History; 24 (4): 551-565, 2000a. doi: 10.1111/01452096.00236

WESTAD, Odd A. Reviewing the Cold War: approaches, interpretations, theory, London, 2000b

WESTAD, Odd A. The Global Cold War: Third World Interventions and the Making of our Times, Cambridge, Cambridge University Press, 2006

ZAHNISER Marvin R.; WEIS W. Michael; A Diplomatic Pearl Harbor? Richard Nixon's Goodwill Mission to Latin America in 1958. Diplomatic History, 13 (2): 163-190, 1989. doi: 10.1111/j.1467-7709.1989.tb00050.x

ZUBOK, Vladislav e PLESHAKOV, Constantine. Inside the Kremlin's Cold War. From Stalin to Krushev. Harvard Universtity Press, 1997

\section{GANPHLAC}

